\title{
Synergy of boric acid and added salts in the catalytic dehydration of hexoses to 5- hydroxymethylfurfural in water
}

Hansen, Thomas Steen; Mielby, Jerrik Jørgen; Riisager, Anders

Published in:

Green Chemistry

Link to article, DOI:

$10.1039 / \mathrm{cogc00355g}$

Publication date:

2011

Document Version

Publisher's PDF, also known as Version of record

Link back to DTU Orbit

Citation (APA):

Hansen, T. S., Mielby, J. J., \& Riisager, A. (2011). Synergy of boric acid and added salts in the catalytic dehydration of hexoses to 5-hydroxymethylfurfural in water. Green Chemistry, 13(1), 109-114.

https://doi.org/10.1039/c0gc00355g

\section{General rights}

Copyright and moral rights for the publications made accessible in the public portal are retained by the authors and/or other copyright owners and it is a condition of accessing publications that users recognise and abide by the legal requirements associated with these rights.

- Users may download and print one copy of any publication from the public portal for the purpose of private study or research.

- You may not further distribute the material or use it for any profit-making activity or commercial gain

- You may freely distribute the URL identifying the publication in the public portal 


\title{
Synergy of boric acid and added salts in the catalytic dehydration of hexoses to 5-hydroxymethylfurfural in water $\dagger$
}

\author{
Thomas S. Hansen, Jerrik Mielby and Anders Riisager* \\ Received 23rd July 2010, Accepted 11th November 2010 \\ DOI: 10.1039/c0gc00355g
}

\begin{abstract}
In combination with various salts boric acid, $\mathrm{B}(\mathrm{OH})_{3}$, was shown to be an efficient, weak Lewis acid catalyst in the aqueous dehydration of fructose to 5-hydroxymethylfurfural (HMF) due to strong complexation between the boron atom and the hexoses. In the dehydration of a highly concentrated aqueous fructose solution ( $30 \mathrm{wt} \%$ ), a $\mathrm{HMF}$ yield of $60 \%$ was achieved at $92 \%$ fructose conversion and a HMF selectivity of $65 \%$ with $100 \mathrm{~g} \mathrm{~L}^{-1} \mathrm{~B}(\mathrm{OH})_{3}$ and $50 \mathrm{~g} \mathrm{~L}^{-1}$ sodium chloride in the aqueous phase and methyl-isobutylketone (MIBK) as extracting solvent. Furthermore, the dehydration of glucose resulted in a yield of $14 \% \mathrm{HMF}$ at $41 \%$ glucose conversion after $5 \mathrm{~h}$ at similar conditions. These results are highly competitive with currently reported aqueous HMF dehydration systems. In combination with the non-corrosive and non-toxic nature of the boric acid, compared to other well known homogeneous catalysts applicable for the dehydration process (e.g., $\mathrm{H}_{2} \mathrm{SO}_{4}$ and $\mathrm{HCl}$ ), clearly, the boric acid-salt mixture is a very attractive catalyst system.
\end{abstract}

\section{Introduction}

Development of novel $\mathrm{CO}_{2}$ neutral and sustainable synthetic strategies to supply fuel and chemicals are necessary as a response to the ongoing concern about the climate changing along with depletion of fossil fuel reserves. Such demands can be met by a shift from the petrochemical industry to one based on biomass as the carbon source..$^{1-6}$

An attractive compound that is obtainable directly from the dehydration of carbohydrates, such as fructose and glucose, is 5-hydroxymethylfurfural (HMF). The molecule constitutes a platform compound that can be converted into a wide range of industrially important chemicals. ${ }^{7,8}$ In this context, the oxidation product of HMF, 2,5-furandicarboxylic acid (FDA), is of specific interest as it can potentially replace terephthalic acid in polyester manufacturing (Scheme 1). ${ }^{9}$

Currently the most successful efforts to produce HMF have been done in ionic liquids, ${ }^{10-12}$ high-boiling organic solvents (e.g. dimethylsulfoxide, DMSO),${ }^{13,14}$ by using strong and highly corrosive mineral acids such as $\mathrm{HCl}, \mathrm{H}_{2} \mathrm{SO}_{4}$ and $\mathrm{H}_{3} \mathrm{PO}_{4}$ with an organic solvent to extract the HMF as it is produced in a two phase system ${ }^{5,15-17}$ or by employing microwaves as the heating source. ${ }^{18-20}$

Herein, we report our results from the development of a novel $^{21}$ method to produce HMF from highly concentrated

Centre for Catalysis and Sustainable Chemistry, Department of Chemistry, Technical University of Denmark, DK-2800 Kgs. Lyngby, Denmark.E-mail: ar@kemi.dtu.dk, thomh@kemi.dtu.dk; Tel: (+45) 45 252233

$\dagger$ Electronic supplementary information (ESI) available: Tables with experimental values reported in the figures. See DOI: $10.1039 / \mathrm{c} 0 \mathrm{gc} 00355 \mathrm{~g}$

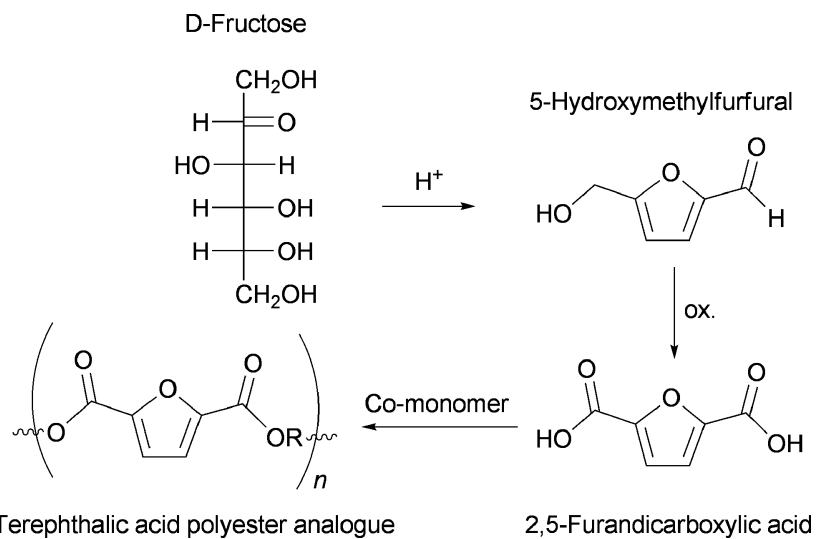

Scheme 1 The reaction path from D-fructose to a terephthalic acid polyester analogue of 2,5-furandicarboxylic acid (FDA).

aqueous fructose solutions employing only a weak, non-toxic and non-corrosive acid, namely boric acid $\left(\mathrm{p} K_{\mathrm{a}}=9.27, T=\right.$ $293.15 \mathrm{~K})^{22}$ as the dehydration catalyst.

\section{Experimental}

\subsection{Materials}

Fructose $(99 \%)$, glucose $(\geq 99.5 \%), \mathrm{B}(\mathrm{OH})_{3}(99.8 \%)$, levulinic acid (98\%), formic acid (99.8\%), methyl-isobutylketone (MIBK) $(\geq 99.0 \%)$, and tetrahydrofuran (THF) $(99.9 \%)$ were purchased from Sigma-Aldrich. 5-Hydroxymethylfurfural (>99\%) was purchased from SAFC and sucrose (99\%) from Alfa Aesar and all used without further purification. Similarly, all salts applied for the salting-out experiments were acquired in p.a. quality and 
used as received. Distilled water was used for preparation of all aqueous solutions.

\subsection{Dehydration of sugars to HMF}

As a general procedure the dehydration of fructose, glucose or sucrose was performed in a sealed pressure stable glass tube (Ace, pressure limit: 20 bar) charged with an aqueous solution of the sugar ( $30 \mathrm{wt} \%, 3.0 \mathrm{~mL}, 5.7 \mathrm{mmol})$, a specified mass of solid $\mathrm{B}(\mathrm{OH})_{3}$ and a magnet. In experiments with organic solvent extraction, these were used in the volume ratio $4: 1$ (org: aq). The tube with the reaction mixture was placed in a preheated oil bath for a specified time under magnetic stirring $(420 \mathrm{rpm})$ at a fixed temperature. After the reaction, the tube was removed from the oil bath and cooled to room temperature before a sample was taken for analysis.

\subsection{Product analysis}

Reaction samples from the fructose, glucose and sucrose experiments were filtered through a syringe filter (VWR, $0.45 \mu \mathrm{m}$ PTFE), mixed with an internal standard $(i-\mathrm{PrOH})$ for calibration and filtered again, prior to analysis by high pressure liquid chromatography (HPLC, Agilent 1200 series, Bio-Rad Aminex HPX-87H, $300 \mathrm{~mm} \times 7.8 \mathrm{~mm}$ pre-packed column). A $0.005 \mathrm{M}$ $\mathrm{H}_{2} \mathrm{SO}_{4}$ mobile phase was employed as eluent at $60{ }^{\circ} \mathrm{C}$ with a

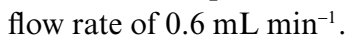

During sucrose analysis the substrate was hydrolyzed to glucose and fructose on the HPLC column resulting in a poor elution profile on the HPLC chromatogram. Thus, in order to analyze experiments with sucrose, an aqueous $30 \mathrm{wt} \%$ solution was hydrolyzed at $50{ }^{\circ} \mathrm{C}$ for $6 \mathrm{~h}$ in $0.05 \mathrm{M} \mathrm{HCl}$ and subsequently analyzed via HPLC. The resulting amount of glucose and fructose was used to determine the initial amount of sucrose.

Concentrations of products were determined from calibration curves obtained with reference samples and corrected with an internal standard, while product yields (\%), product selectivities $(\%)$ and fructose conversions (\%) were based on the initial concentration of sugars and calculated as:

$$
\begin{aligned}
& \text { Product yield }=\frac{\text { Product conc. }}{\text { Initial sugar conc. }} \times 100 \% \\
& \text { Sugar conversion }=\left(1-\frac{\text { Sugar conc. }}{\text { Initial sugar conc. }}\right) \times 100 \% \\
& \text { Product selectivity }=\frac{\text { Product yield }}{\text { Sugar conversion }} \times 100 \%
\end{aligned}
$$

The mass balances did not add up to $100 \%$ due to formation of insoluble polymers (humins), soluble polymers and other unidentified products during the dehydration process.

\section{Results and discussion}

\subsection{Boric acid}

Boric acid, $\mathrm{B}(\mathrm{OH})_{3}$ or $\mathrm{H}_{3} \mathrm{BO}_{3}$, acts as a Lewis acid in aqueous solutions forming tetrahydroxyborate and a proton (or hydronium ion) upon reaction with water. The nature of the boric acid suggests (based on previous published results by Kuster and Temmink ${ }^{23}$ ) that it is too weak an acid to efficiently catalyze the dehydration reaction of fructose to HMF. However, boric acid forms strong chelates with diols and hexoses, e.g. fructose and glucose ${ }^{24-26}$ shifting the equilibrium reactions towards a doubly coordinated borate-hexose complex. This complexation results in an overall release of protons leading to acidification of the aqueous media and so facilitates the acid catalyzed dehydration (Scheme 2).
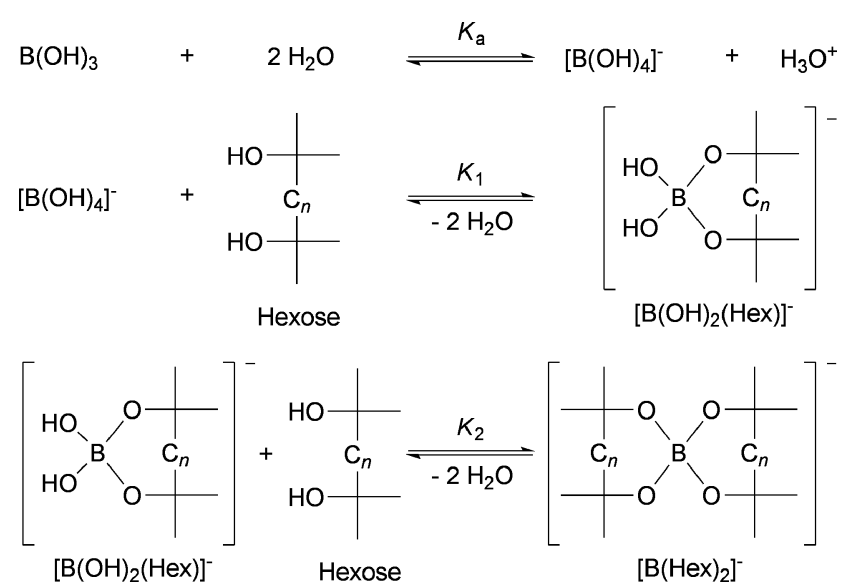

Scheme 2 Equilibria between boric acid and hexoses in water.

In principle, the $\mathrm{pH}$ will gradually increase during the HMF dehydration reaction and return to a value determined by the boric acid-water equilibrium when all sugars are converted. However, by-product formation of formic acid (FA) and levulinic acid (LA) by competitive rehydration of HMF during the reaction ${ }^{27,28}$ prevent the $\mathrm{pH}$ from increasing. From a downstream HMF processing point of view, this phenomenon could prove very useful, as the isolation of LA and FA, which are also valuable by-products, results in a HMF product solution which is not nearly as acidic compared to using mineral acids. This is likely to make the overall HMF production process more economically attractive by reducing costs related to both neutralization and the use of corrosion resistant materials.

\subsection{Titration of fructose and glucose with boric acid}

A $1.88 \mathrm{M}$ aqueous solution of fructose and a $1.93 \mathrm{M}$ solution of glucose (both $\sim 30 \mathrm{wt}^{\%} \%$ ) were titrated with solid $\mathrm{B}(\mathrm{OH})_{3}$ to the point of saturation at room temperature to monitor the associated $\mathrm{pH}$ change as a function of the $\mathrm{B}(\mathrm{OH})_{3}$ concentration (Fig. 1). As reference, $\mathrm{pH}$ was measured in a $\mathrm{B}(\mathrm{OH})_{3}$ saturated $\left(50 \mathrm{~g} \mathrm{~L}^{-1}\right)$ aqueous solution $(\mathrm{pH}=3.65)$.

A rapid decrease in $\mathrm{pH}$ in the $30 \mathrm{wt} \%$ sugar solutions was observed upon the first boric acid addition which then levelled out as more $\mathrm{B}(\mathrm{OH})_{3}$ was added. The change was more pronounced for fructose than glucose suggesting a stronger complexation between $\mathrm{B}(\mathrm{OH})_{3}$ and fructose than with glucose, in accordance with previous findings. ${ }^{25}$

\subsection{Dehydration of fructose with boric acid}

The dehydration of fructose to HMF is known to proceed even without the addition of catalyst at elevated temperatures and prolonged reaction times. ${ }^{14}$ However, when the dehydration of fructose is carried out in an aqueous environment alone high 


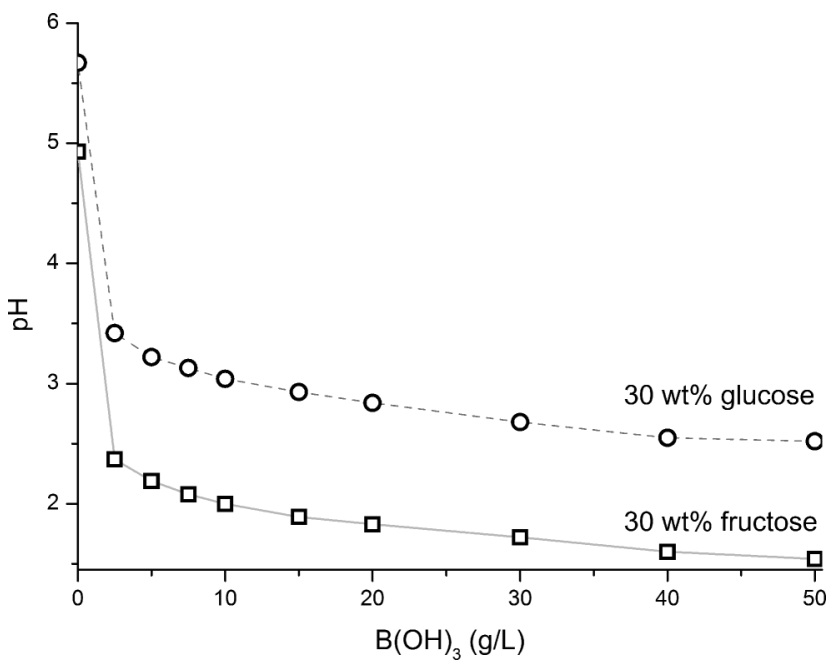

Fig. 1 Titration of a $1.88 \mathrm{M}$ fructose solution and a $1.93 \mathrm{M}$ glucose solution (both $\sim 30 \mathrm{wt} \%$ ) with solid $\mathrm{B}(\mathrm{OH})_{3}$. Between additions of boric acid, the system was allowed sufficient time to stabilize before $\mathrm{pH}$ measurements.

HMF yields and selectivities are difficult to achieve. One way to overcome this problem is by employing an organic phase that extracts $\mathrm{HMF}$ as it is produced thereby reducing the rehydration of HMF to FA and LA, as well as humin formation to some extent. ${ }^{15,16}$ To separate this inherent catalytic effect from any effects of the added catalyst, reaction temperature and time was initially investigated in order to find conditions where the non-catalyzed reaction was negligible. Here it was found, that reaction of a $30 \mathrm{wt} \%$ fructose solution at $150{ }^{\circ} \mathrm{C}$ for $45 \mathrm{~min}$ with MIBK as the extracting solvent with a MIBK : aqueous volume ratio of $4: 1$ possessed minimal intrinsic activity resulting in only $5 \%$ fructose conversion and 2\% HMF yield (Fig. 2). Notably, these conditions are, however, still suitable for HMF production if a dehydration catalyst is added (vide infra).

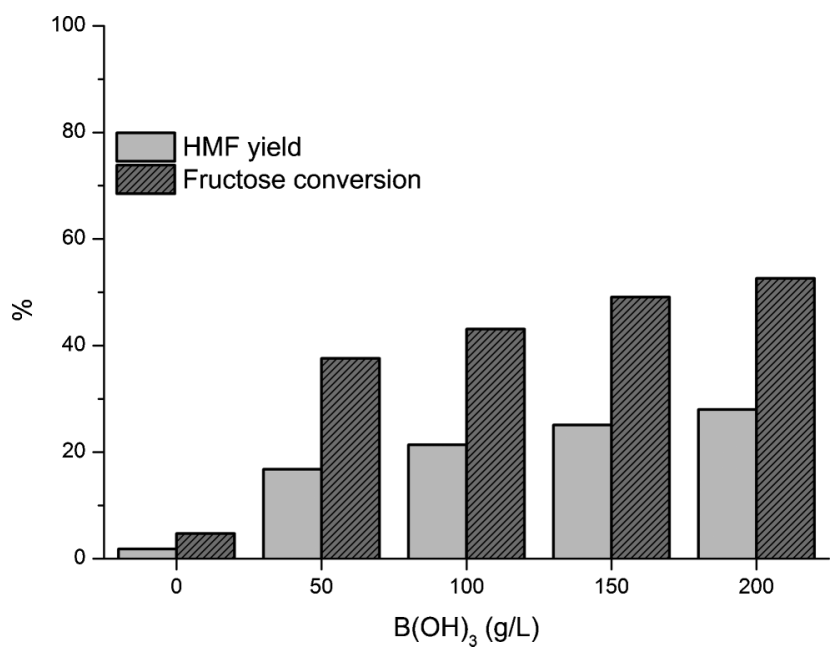

Fig. 2 Dehydration of $30 \mathrm{wt} \%$ fructose solutions with varied $\mathrm{B}(\mathrm{OH})_{3}$ concentrations and MIBK as extracting solvent $\left(150{ }^{\circ} \mathrm{C}, 45 \mathrm{~min}\right.$, MIBK : aqueous volume ratio $=4: 1$ ).

Using the reaction conditions where the intrinsic conversion to $\mathrm{HMF}$ was found to be minimal (i.e. $150{ }^{\circ} \mathrm{C}, 45 \mathrm{~min}$, MIBK : aqueous volume ratio $=4: 1$ ), a set of experiments were conducted varying the catalyst amount in a $30 \mathrm{wt} \%$ fructose solution in order to investigate how the $\mathrm{B}(\mathrm{OH})_{3}$ concentration influenced the dehydration of highly concentrated fructose solutions (Fig. 2).

A clear relation between the $\mathrm{B}(\mathrm{OH})_{3}$ concentration and the fructose conversion was found, showing an increase in fructose conversion with increasing $\mathrm{B}(\mathrm{OH})_{3}$ concentration. The most commonly used catalysts for the dehydration process are strong acids, as previously mentioned, so increasing the amount of the weak Lewis acid $\mathrm{B}(\mathrm{OH})_{3}$ was expected to result in a higher fructose conversion and HMF yield.

\subsection{Synergetic catalytic effect between boric acid and salts}

When sugars are dehydrated to HMF in acidic, aqueous-organic systems with dissolved salts, the salts usually facilitate only a salting-out effect of the formed HMF to the organic phase and no significant catalytic effect. ${ }^{16}$ In accordance with this, only a weak catalytic effect of $\mathrm{NaCl}$ was found in the dehydration of $30 \mathrm{wt} \%$ aqueous fructose solution (Fig. 3).

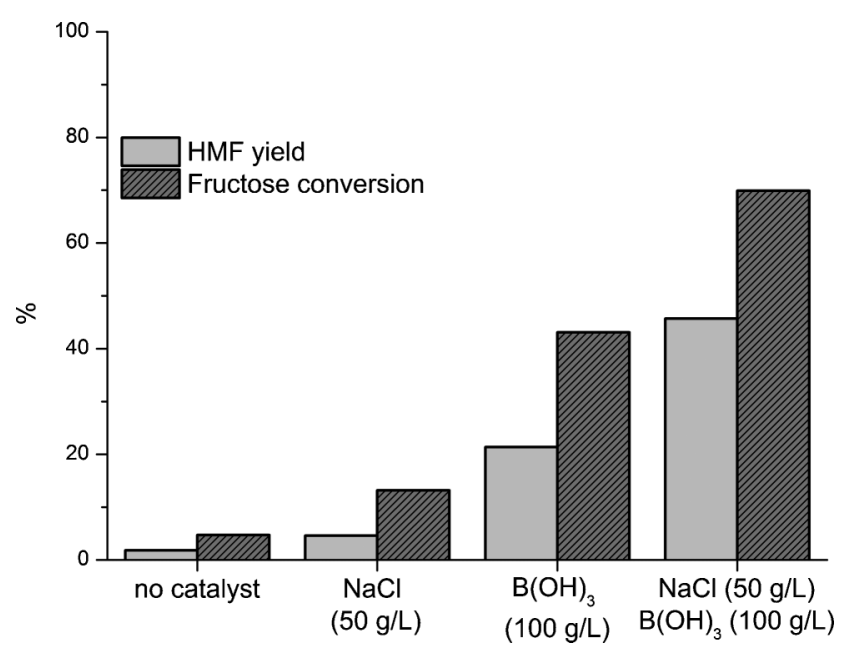

Fig. 3 Dehydration of $30 \mathrm{wt} \%$ fructose solutions with MIBK as extracting solvent and no catalyst or added $\mathrm{NaCl}$ and/or $\mathrm{B}(\mathrm{OH})_{3}$ $\left(150{ }^{\circ} \mathrm{C}, 45 \mathrm{~min}, \mathrm{MIBK}\right.$ : aqueous volume ratio $\left.=4: 1\right)$.

The addition of $50 \mathrm{~g} \mathrm{~L}^{-1} \mathrm{NaCl}$ to the reaction mixture resulted in a HMF yield of $5 \%$ at $13 \%$ fructose conversion compared to $2 \% \mathrm{HMF}$ at $5 \%$ fructose conversion without $\mathrm{NaCl}$ present. This weak catalytic effect is believed to arise from the slight acidification observed when salts are added to a concentrated solution of fructose. The dehydration reaction of fructose to HMF is highly dependent on the $\mathrm{pH}$ in solution, hence a small decrease in $\mathrm{pH}$ is expected to have a positive influence on the rate of fructose conversion and HMF formation.

Surprisingly the addition of $\mathrm{NaCl}$ in low concentrations together with $\mathrm{B}(\mathrm{OH})_{3}$ was found not only to increase the HMF yield, due to the salting-out effect as described by RománLeshkov and Dumesic, ${ }^{16}$ but also to significantly increase the fructose conversion and $\mathrm{HMF}$ yield. Thus, reaction at $150{ }^{\circ} \mathrm{C}$ for 45 min with $50 \mathrm{~g} \mathrm{~L}^{-1} \mathrm{NaCl}, 100 \mathrm{~g} \mathrm{~L}^{-1} \mathrm{~B}(\mathrm{OH})_{3}$ and MIBK as extracting solvent (MIBK : aqueous volume ratio $=4: 1$ ) resulted in a fructose conversion of $70 \%$ and $46 \%$ HMF yield (Fig. 3). The synergistic effect of using both $\mathrm{B}(\mathrm{OH})_{3}$ and $\mathrm{NaCl}$ is believed to occur as a result of the increased acidity of aqueous 
Table 1 Dehydration of $30 \mathrm{wt} \%$ fructose solutions with boric acid, various salts and MIBK extraction ${ }^{a}$

\begin{tabular}{llllll}
\hline Entry & Salt & $\begin{array}{l}\text { Fructose } \\
\text { conversion (\%) }\end{array}$ & $\begin{array}{l}\text { HMF } \\
\text { yield (\%) }\end{array}$ & $\begin{array}{l}\text { HMF } \\
\text { selectivity (\%) }\end{array}$ & $\begin{array}{l}R \text { value }^{b} \\
\text { (MIBK : aq) }\end{array}$ \\
\hline 1 & $\mathrm{LiCl}$ & 69 & 45 & 66 & 1.1 \\
2 & $\mathrm{LiBr}$ & 61 & 38 & 62 & 1.0 \\
3 & $\mathrm{LiNO}_{3}$ & 49 & 21 & 42 & 0.9 \\
4 & $\mathrm{NaCl}$ & 70 & 46 & 65 & 1.0 \\
5 & $\mathrm{NaBr}$ & 60 & 38 & 64 & 0.9 \\
6 & $\mathrm{NaNO}_{3} 49$ & 20 & 41 & 0.9 \\
7 & $\mathrm{Na}_{2} \mathrm{SO}_{4}$ & 90 & 41 & 45 & 1.7 \\
8 & $\mathrm{KCl}_{9}$ & 67 & 44 & 65 & 1.0 \\
9 & $\mathrm{KBr}_{10}$ & 63 & 39 & 62 & 0.9 \\
10 & $\mathrm{KI}_{11} 56$ & 35 & 63 & 0.7 \\
11 & $\mathrm{KNO}_{3}$ & 49 & 20 & 40 & 0.8 \\
12 & $\mathrm{~K}_{2} \mathrm{SO}_{4}$ & 89 & 40 & 46 & 1.5 \\
13 & $\mathrm{MgCl}_{2}$ & 81 & 52 & 65 & 1.1 \\
14 & $\mathrm{AlCl}_{3}$ & 100 & 21 & 21 & 1.1 \\
15 & $\mathrm{FeCl}_{3}$ & 99 & 36 & 36 & 1.1
\end{tabular}

${ }^{a}$ Reaction conditions: $100 \mathrm{~g} \mathrm{~L}^{-1} \mathrm{~B}(\mathrm{OH})_{3}, 0.87 \mathrm{M}$ salt with respect to the anion, $45 \mathrm{~min}, 150{ }^{\circ} \mathrm{C}$, MIBK : aqueous volume ratio $=4: 1 .{ }^{b}$ The $R$ value is the HMF distribution obtained between the MIBK phase and the aqueous phase, i.e. $[\mathrm{HMF}]_{\mathrm{MIBK}} /[\mathrm{HMF}]_{\mathrm{aq}}$.

$\mathrm{B}(\mathrm{OH})_{3}$ solutions in combination with salts, suggesting that the salts stabilizes one or more of the charged intermediates and products shown in Scheme 2. The acidifying effect of different salts on boric acid has been correlated to the energy of hydration by Shishido ${ }^{29}$ and shows an increase in acidity with increasing hydration energy. As already mentioned, the addition of salt to a concentrated fructose solution also results in a slight acidification of the solution. Hence, several factors add up in the observed synergy and complex behavior of $\mathrm{NaCl}$ and $\mathrm{B}(\mathrm{OH})_{3}$ in the dehydration of aqueous fructose solutions to HMF.

An experiment was conducted in order to find the highest obtainable HMF yield from a $30 \mathrm{wt} \%$ aqueous fructose solution near full substrate conversion with the $\mathrm{NaCl}$-containing catalytic system. Increasing the reaction time to $90 \mathrm{~min}$ subsequently resulted in a $92 \%$ fructose conversion, a $60 \%$ HMF yield and a HMF selectivity of $65 \%$.

A range of other salts, primarily containing alkali or alkaline earth metal cations, were further employed in the dehydration of fructose in order to investigate the influence of the salts on the synergistic interplay with $\mathrm{B}(\mathrm{OH})_{3}$ (Table 1).

A clear relationship between the nature of the anion and the resulting fructose conversion and HMF yield was observed. Generally, sulfates (entries 7 and 12) resulted in high fructose conversions and a high HMF distribution in the organic phase but low HMF selectivities and yields. The phase distribution selectivity is commonly expressed as the $R$ value (calculated as $[\mathrm{HMF}]_{\text {org }} /[\mathrm{HMF}]_{\mathrm{aq}}$ ), which quantify the extracting power of the organic solvent. In contrast, the nitrates (entries 3, 6 and 11) resulted in lower fructose conversions, HMF yields, HMF selectivities and $R$ values compared to the halide salts, which were shown to be superior when comparing HMF yields and selectivities. The size of the halide anions did not seem to affect the selectivity towards HMF, whereas the fructose conversion rate decreased in the order: chloride $>$ bromide $>$ iodide.

The nature of the alkali cation did also not seem to have great importance on the dehydration reaction and only small variations in $\mathrm{HMF}$ yields and selectivities within the estimated experiment error were observed. Similar trends were observed in the control experiments conducted without $\mathrm{B}(\mathrm{OH})_{3}$ in order to test the activity of the salts alone (results not presented here).

Interestingly, the high $R$ values, representing the distribution of HMF in the organic phase relative to the aqueous phase, observed in experiments with sulfate salts did not result in correspondingly high relative HMF yields and selectivities, as would be expected when the mean residence time of HMF in the aqueous solution was reduced due to diminished rehydration. The same conclusion was reached by Román-Leshkov and Dumesic ${ }^{16}$ in their investigation of fructose dehydration reactions employing different salts and a strong mineral acid as the dehydration catalyst, thus suggesting the sulfate anion has some influence on the dehydration reactivity, e.g. shifting the pyranose-furanose equilibrium.

In combination, the strong Lewis acidic salts, $\mathrm{AlCl}_{3}$ or $\mathrm{FeCl}_{3}$, and $\mathrm{B}(\mathrm{OH})_{3}$ (entries 14 and 15) resulted in formation of large amounts of polymers and the rehydration products FA and LA, demonstrating that HMF was no longer the favored product.

\subsection{Boric acid-salt catalysis with common extracting solvents}

Experiments with different organic extraction solvents were conducted with $30 \mathrm{wt} \%$ fructose solutions at $150{ }^{\circ} \mathrm{C}$ for $45 \mathrm{~min}$ with $100 \mathrm{~g} \mathrm{~L}^{-1}$ of $\mathrm{B}(\mathrm{OH})_{3}$ catalyst and $50 \mathrm{~g} \mathrm{~L}^{-1} \mathrm{NaCl}$ using an organic : aqueous volume ratio of $4: 1$. (Fig. 4).

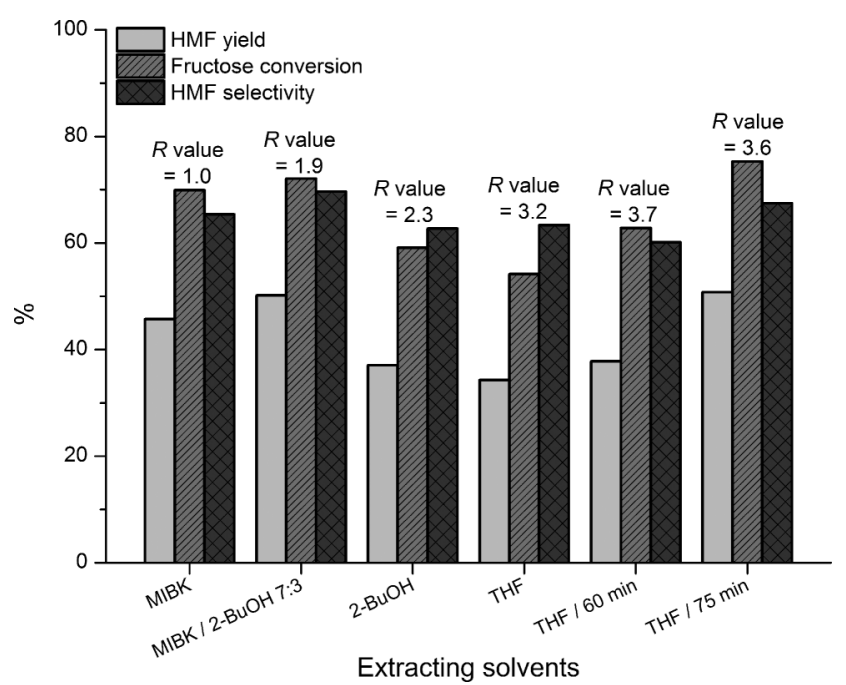

Fig. 4 Dehydration of $30 \mathrm{wt} \%$ fructose solutions with organic extraction solvents, $100 \mathrm{~g} \mathrm{~L}^{-1} \mathrm{~B}(\mathrm{OH})_{3}$ and $50 \mathrm{~g} \mathrm{~L}^{-1} \mathrm{NaCl}\left(150^{\circ} \mathrm{C}, 45\right.$ min unless otherwise mentioned, organic: aqueous volume ratio $=4: 1)$.

Reactions with THF as extraction solvent were found to be substantially slower than analogous reactions with MIBK. This could be attributed to an effective decrease in the fructose concentration at elevated temperatures as a result of miscibility of THF and saline aqueous mixtures, or an increased ability of THF to extract the produced organic acids compared to MIBK. However, when increasing the reaction time with THF as extracting solvent comparable HMF yields and selectivities to experiments with MIBK were obtained. 
Table 2 Dehydration of $30 \mathrm{wt} \%$ glucose solutions with and without boric acid and $\mathrm{NaCl}$ and MIBK extraction

\begin{tabular}{llllll}
\hline Entry Catalyst & $\begin{array}{l}\text { Time } \\
(\mathrm{min})\end{array}$ & $\begin{array}{l}\text { Glucose con- } \\
\text { version (\%) }\end{array}$ & $\begin{array}{l}\text { HMF } \\
\text { yield (\%) }\end{array}$ & $\begin{array}{l}\text { HMF select- } \\
\text { ivity (\%) }\end{array}$ \\
\hline $1^{a}$ & - & 45 & $<1$ & 0 & 0 \\
$2^{b}$ & $\mathrm{~B}(\mathrm{OH})_{3}+\mathrm{NaCl}$ & 45 & 8 & 2 & 25 \\
$3^{a}$ & - & 180 & 13 & 1 & 10 \\
$4^{b}$ & $\mathrm{~B}(\mathrm{OH})_{3}+\mathrm{NaCl}$ & 180 & 36 & 10 & 27 \\
$5^{a}$ & - & 300 & 24 & 3 & 13 \\
$6^{b}$ & $\mathrm{~B}(\mathrm{OH})_{3}+\mathrm{NaCl}$ & 300 & 41 & 14 & 34
\end{tabular}

${ }^{a}$ Reaction conditions: $150{ }^{\circ} \mathrm{C}$, MIBK : aqueous volume ratio $=4: 1$. ${ }^{b}$ Reaction conditions: $100 \mathrm{~g} \mathrm{~L}^{-1} \mathrm{~B}(\mathrm{OH})_{3}, 50 \mathrm{~g} \mathrm{~L}^{-1} \mathrm{NaCl}, 150{ }^{\circ} \mathrm{C}$, MIBK : aqueous volume ratio $=4: 1$.

THF is an interesting extraction solvent for the dehydration reaction due to avoidance of humin formation which, if formed, would impose a severe drawback from a process point of view. Although the apparent HMF selectivity with THF was not significantly higher than experiments with visible humin formation, the selectivity was observed to increase with increasing reaction time, most likely due to reversion of isomeric and dimer forms of fructose. The disadvantage and concern of applying THF is obviously its low flashpoint $\left(-14^{\circ} \mathrm{C}\right)$, its tendency to form peroxides over time and the relatively high chemical aggressiveness of THF fumes. Unfortunately, the latter made longer term experiments ( $>75 \mathrm{~min}$ ) impossible with our available apparatus.

\subsection{Dehydration of glucose with boric acid}

Despite the ability to selectively form HMF from fructose, boric acid proved ineffective in the dehydration of glucose to $\mathrm{HMF}$. Thus, dehydration of a $30 \mathrm{wt}^{\%} \%$ glucose solution at $150{ }^{\circ} \mathrm{C}$ for 45 min with $100 \mathrm{~g} \mathrm{~L}^{-1} \mathrm{~B}(\mathrm{OH})_{3}$ and $50 \mathrm{~g} \mathrm{~L}^{-1} \mathrm{NaCl}$ only resulted in $8 \%$ glucose conversion and a poor HMF yield of $2 \%$ (Table 2 , entry 2). Prolonging the reaction time to $3 \mathrm{~h}$ increased the $\mathrm{HMF}$ yield somewhat to $10 \%$ at $36 \%$ glucose conversion compared to the un-catalyzed reaction which only resulted in $1 \% \mathrm{HMF}$ yield at $13 \%$ glucose conversion (entries 3 and 4). Further increase of the reaction time to $5 \mathrm{~h}$ resulted in a $41 \%$ glucose conversion and $14 \%$ HMF yield compared to the un-catalyzed experiment which resulted in a $24 \%$ glucose conversion and $3 \% \mathrm{HMF}$ yield (entries 5 and 6). Thus, even though the catalytic system performed poorly on a glucose feedstock, the catalyzed reactions were substantially better than the un-catalyzed ones.

The dehydration of glucose is much more difficult than the dehydration of fructose, presumably because the first step in the Lobry de Bruyn-van Ekenstein transformation ${ }^{30}$ of glucose to fructose proceeds rapidly in basic media, but very slowly in acidic media where HMF production is possible. Furthermore the HMF selectivity increased over time indicating that some intermediate hexoses formed from glucose were able to revert back to fructose and dehydrate to HMF.

\subsection{Dehydration of sucrose with boric acid}

The disaccharide sucrose consists of a fructose unit and a glucose unit connected via an $\alpha-1,4^{\prime}$-glycosidic linkage which can be hydrolyzed relatively easily. Indeed, the fructose part of the disaccharide could selectively be converted into HMF by the
Table 3 Dehydration of $30 \mathrm{wt} \%$ sucrose solutions with boric acid, $\mathrm{NaCl}$ and MIBK extraction ${ }^{a}$

\begin{tabular}{llllll}
\hline $\begin{array}{c}\text { Time } \\
\text { Entry }\end{array}$ & $\begin{array}{l}\text { Glucose } \\
\text { yield (\%) }\end{array}$ & $\begin{array}{l}\text { Fructose } \\
\text { yield (\%) }\end{array}$ & HMF yield (\%) & $\begin{array}{l}\text { HMF select- } \\
\text { ivity }^{b}(\%)\end{array}$ \\
\hline 1 & 45 & 40 & 17 & 21 & 64 \\
2 & 90 & 40 & 7 & 30 & 70 \\
3 & 105 & 39 & 4 & 32 & 70 \\
4 & 120 & 38 & 3 & 33 & 70
\end{tabular}

${ }^{a}$ Reaction conditions: $100 \mathrm{~g} \mathrm{~L}^{-1} \mathrm{~B}(\mathrm{OH})_{3}, 50 \mathrm{~g} \mathrm{~L}^{-1} \mathrm{NaCl}, 150{ }^{\circ} \mathrm{C}$, MIBK : aqueous volume ratio $=4: 1 .{ }^{b}$ Selectivity from the fructose part of sucrose.

catalytic $\mathrm{B}(\mathrm{OH})_{3}-\mathrm{NaCl}$ system. Interestingly, the glucose part was not converted in any significant amount and could still be detected after the dehydration reaction. At prolonged reaction times of $2 \mathrm{~h}$ at $150^{\circ} \mathrm{C}$ with a $30 \mathrm{wt} \%$ aqueous sucrose solution, $94 \%$ of the initial fructose units were converted resulting in a good HMF yield of $33 \%$ from sucrose corresponding to a $70 \%$ selectivity assuming that all HMF originated from fructose (Table 3). ${ }^{31}$

\section{Conclusions}

In this work, we have shown that the Lewis acid, boric acid $\mathrm{B}(\mathrm{OH})_{3}$, is a very efficient catalyst in the dehydration of highly concentrated aqueous fructose solutions to HMF. This result, combined with desirable properties such as non-toxicity, low corrosiveness, low acid strength and readily availability, makes $\mathrm{B}(\mathrm{OH})_{3}$ a very attractive alternative to known catalysts for the process. ${ }^{32}$ HMF selectivities and yields were further improved by employing a combined catalytic system of $\mathrm{B}(\mathrm{OH})_{3}$ and $\mathrm{NaCl}$, which in combination showed a synergistic effect on the dehydration reaction.

Boric acid in combination with $\mathrm{NaCl}$ was found to be less efficient for the dehydration of glucose in water, which is also generally considered to be a more challenging task to achieve. Hence, only poor HMF yields were accomplished. However, the catalytic system developed here performed much better than the un-catalyzed reaction and could also be applied for highly concentrated aqueous sucrose solutions.

This study is, to the best of our knowledge, the first to demonstrate the use of boric acid in the dehydration of sugars to $\mathrm{HMF}$ and to provide a detailed parameter study of the dehydration process for fructose. A simple modification of the catalytic system by addition of salt was shown to have a synergistic effect of the dehydration of fructose to HMF allowing good yields and selectivities of HMF to be reached.

Since boric acid is a weak Lewis acid, non-toxic, cheap and already widely used in industrial processes it is desirable from an industrial point of view compared to other mineral acids such as $\mathrm{HCl}$ and $\mathrm{H}_{2} \mathrm{SO}_{4}$, which are highly corrosive. This could clearly make future implementation of $\mathrm{B}(\mathrm{OH})_{3}$ in $\mathrm{HMF}$ production attractive compared to other acids.

\section{Acknowledgements}

The work was supported by The Danish National Advanced Technology Foundation and Novozymes A/S. 


\section{Notes and references}

1 B. Kamm and M. Kamm, Appl. Microbiol. Biotechnol., 2004, 64, 137.

2 B. Kamm and M. Kamm, Adv. Biochem. Eng./ Biotechnol., 2007, 105, 175.

3 C. H. Christensen, J. Rass-Hansen, C. C. Marsden, E. Taarning and K. Egeblad, ChemSusChem, 2008, 1, 283.

4 A. J. Ragauskas, C. K. Williams, B. H. Davison, G. Britovsek, J. Cairney, C. A. Eckert, W. J. Frederick Jr., J. P. Hallett, D. J. Leak, C. L. Liotta, J. R. Mielenz, R. Murphy, R. Templer and T. Tschaplinski, Science, 2006, 311, 484.

5 Y. Román-Leshkov, C. J. Barrett, Z. Y. Liu and J. A. Dumesic, Nature, 2007, 447, 982

6 M. Mascal and E. B. Nikitin, Angew. Chem., Int. Ed., 2008, 47, 7924.

7 A. Corma, S. Iborra and A. Velty, Chem. Rev., 2007, 107, 2411.

8 C. Moreau, M. N. Belgacem and A. Gandini, Top. Catal., 2004, 27, 11.

9 T. Werpy and G. Petersen, US DOE, 2004, No. DOE/GO-1020041992, http://www.nrel.gov/docs/fy04osti/35523.pdf.

10 H. Zhao, J. E. Holladay, H. Brown and Z. C. Zhang, Science, 2007, 316, 1597.

11 G. Yong, Y. Zhang and J. Y. Ying, Angew. Chem., Int. Ed., 2008, 47, 9345.

12 T. Ståhlberg, M. G. Sørensen and A. Riisager, Green Chem., 2010, 12, 321 .

13 J. N. Chheda, Y. Román-Leshkov and J. A. Dumesic, Green Chem., 2007, 9, 342 .

14 R. M. Musau and R. M. Munavu, Biomass, 1987, 13, 67.

15 Y. Román-Leshkov, J. N. Chheda and J. A. Dumesic, Science, 2006, 312, 1933.

16 Y. Román-Leshkov and J. A. Dumesic, Top. Catal., 2009, 52, 297.

17 B. F. M. Kuster, Starch/Staerke, 1990, 42, 314.
18 X. Qi, M. Watanabe, T. M. Aida and R. L. Smith, Jr., Green Chem., 2008, 10, 799.

19 X. Qi, M. Watanabe, T. M. Aida and R. L. Smith, Jr., Catal. Commun., 2008, 9, 2244.

20 T. S. Hansen, J. M. Woodley and A. Riisager, Carbohydr. Res., 2009, 344, 2568.

21 Although $\mathrm{B}(\mathrm{OH})_{3}$ is mentioned as a possible catalyst for the dehydration of fructose to HMF in at least three patent applications by Dumesic et al: : WO 2007/146636, WO 2008/151178 A1 and US 2008/0033188 A1, no experimental results are reported.

22 Handbook of Chemistry and Physics, CRC, 2008-2009, 89, pp. 8-40.

23 B. F. M. Kuster and H. M. G. Temmink, Carbohydr. Res., 1977, 54, 185.

24 J. C. Norrild and H. Eggert, J. Am. Chem. Soc., 1995, 117, 1479 .

25 M. Makkee, A. P. G. Kieboom and H. van Bekkum, Recl. Trav. Pays-Bas., 1985, 104, 230.

26 M. van Duin, J. A. Peters, A. P. C. Kieboom and H. van Bekkum, Tetrahedron, 1984, 40, 2901.

27 L. Cottier and G. Descotes, Trends in Heterocycl. Chem., 1991, 2, 233.

28 J. Horvat, B. Klaić, B. Metelko and V. Šunjić, Tetrahedron Lett., 1985, 26, 2111.

29 S. Shishido, Bull. Chem. Soc. Jpn., 1952, 25, 199.

30 W. L. Evans, Chem. Rev., 1942, 31, 537.

31 To assume that all HMF originates from the fructose moiety of sucrose is not entirely correct, as dehydration experiments with pure glucose indeed indicated that a small amount was converted to HMF. However, we have rationalized that this is the best way of indicating the selectivity of the sucrose dehydration.

32 A. Boisen, T. B. Christensen, W. Fu, Y. Y. Gorbanev, T. S. Hansen, J. S. Jensen, S. K. Klitgaard, A. Riisager, T. Ståhlberg and J. M. Woodley, Chem. Eng. Res. Des., 2009, 87, 1318. 